\title{
Discussion on a coupled fixed point theorem for single-valued operators in b-metric spaces
}

\section{Yanbin Sang*, Dongxia Zhao}

Department of Mathematics, North University of China, Taiyuan, Shanxi, 030051, China.

\author{
Communicated by B. Samet
}

\begin{abstract}
In this note, an existence and uniqueness theorem of fixed points for single-valued mappings in partially ordered b-metric spaces is established. As a corollary, the contraction constant for a coupled fixed point theorem obtained in a recent paper is relaxed from $\left[0, \frac{1}{s}\right)$ to $[0,1)$. Furthermore, a system of integral equation is also discussed. (c) 2017 All rights reserved.
\end{abstract}

Keywords: b-metric space, contractive condition, partial order, coupled fixed point, mixed monotone operator. 2010 MSC: 47H10, 54H25.

\section{Introduction}

In recent years, there was much attention focused on contractive operators in b-metric spaces. Czerwik $[4,5]$ introduced the concept of a b-metric space.

Definition $1.1([4,5])$. Let $X$ be a set and let $s \geqslant 1$ be a given real number. A functional $d: X \times X \longrightarrow \mathbb{R}_{+}$ is said to be a b-metric if the following conditions are satisfied:

(i) if $x, y \in X$, then $d(x, y)=0$ if and only if $x=y$;

(ii) $d(x, y)=d(y, x)$, for all $x, y \in X$;

(iii) $d(x, z) \leqslant s[d(x, y)+d(y, z)]$, for all $x, y, z \in X$.

A pair $(X, d)$ is called a $b$-metric space.

Since then, several authors have established the existence and uniqueness theorems of fixed points for single-valued operators in b-metric spaces $[2,3,6,11,13,15]$.

On the other hand, there has been growing interest in coupled fixed points for mixed monotone operators. It is well-known that the notion of a coupled fixed point was introduced and studied by

\footnotetext{
*Corresponding author

Email addresses: syb6662004@163.com (Yanbin Sang), zhaodongxia6@sina.com (Dongxia Zhao)
} 
Opoĭcev [14] and then by Guo and Lakshmikantham [9]. Their study has not only directly unified the results of increase and decrease operators, but also wide applications in engineering, nuclear physics, biological chemistry technology, etc. $[1,7,8,10]$. In partially ordered spaces, we usually suppose the concave-convex type conditions or contraction conditions to study the existence and uniqueness of fixed points of mixed monotone operators without compact condition [10,12, 16-18]. Very recently, Bota et al. [2] proved some coupled fixed point theorems for mixed monotone operators in complete b-metric spaces. The tool was based on the iterative construction of a Cauchy successive approximations sequence. Their main result is the following.

Theorem $1.2([2])$. Let $(\mathrm{X}, \mathrm{d})$ be a complete $\mathrm{b}$-metric space with $\mathrm{s} \geqslant 1$ and $\mathrm{T}: \mathrm{X} \times \mathrm{X} \longrightarrow \mathrm{X}$ a continuous mapping with the mixed monotone property on $\mathrm{X} \times \mathrm{X}$. Assume that the following conditions are satisfied:

(i) there exists $k \in\left[0, \frac{1}{s}\right)$ such that

$$
d(T(x, y), T(u, v)) \leqslant \frac{k}{2}[d(x, u)+d(y, v)], \quad \forall x \geqslant u, y \leqslant v ;
$$

(ii) there exist $\mathrm{x}_{0}, \mathrm{y}_{0} \in X$ such that $\mathrm{x}_{0} \leqslant \mathrm{~T}\left(\mathrm{x}_{0}, \mathrm{y}_{0}\right)$ and $\mathrm{y}_{0} \geqslant \mathrm{~T}\left(\mathrm{y}_{0}, \mathrm{x}_{0}\right)$.

Then there exist $x, y \in X$ such that $x=T(x, y)$ and $y=T(y, x)$.

Question 1.3. Does the conclusion of Theorem 1.2 remain true for every $k \in\left[\frac{1}{s}, 1\right)$ ?

The purpose of this paper is to present some fixed point theorems for single-valued mappings in partially ordered b-metric spaces, and gives a positive answer to Question 1.3. In essence, our results do not depend on the triangle inequality. Our ideas come from $[4,6,11]$. Furthermore, a system of integral equation which is the same as Theorem 4.1 in [2] is discussed. Finally, we point out that Samet et al. [18] and Roldan et al. [17] have showed that coupled and multi-dimensional fixed point theorems can be obtained as easy consequences of fixed point results in dimension one in the setup of partially metric spaces. Therefore, our results can be applied directly to the coupled fixed points of mixed monotone operators and multi-dimensional fixed points theorems [16].

\section{Preliminaries}

Before presenting our results, we collect relevant definitions and results which will be needed in the proof of our main results. Denote with $\mathbb{N}$ the set of positive integers.

Let $(X, \leqslant)$ be a partially ordered set equipped with a metric $d$ and $F: X \times X \rightarrow X$ be a given mapping. We endow the product set $X \times X$ with the following partial order:

$$
\left(x_{1}, x_{2}\right),\left(y_{1}, y_{2}\right) \in X \times X, \quad\left(x_{1}, x_{2}\right) \leqslant 2\left(y_{1}, y_{2}\right) \Longleftrightarrow x_{1} \leqslant y_{1}, x_{2} \geqslant y_{2} .
$$

Definition 2.1. $F$ is said to have the mixed monotone property if $F(x, y)$ is monotone non-decreasing in $x$ and is monotone non-increasing in $y$, that is, for every $x, y \in X$,

$$
\begin{aligned}
& x_{1}, x_{2} \in X, x_{1} \leqslant x_{2} \Longrightarrow F\left(x_{1}, y\right) \leqslant F\left(x_{2}, y\right) \\
& y_{1}, y_{2} \in X, y_{1} \geqslant y_{2} \Longrightarrow F\left(x, y_{1}\right) \leqslant F\left(x, y_{2}\right) .
\end{aligned}
$$

It is easy to show that the mappings $\eta, \delta: X^{2} \times X^{2} \longrightarrow[0,+\infty)$ defined by

$$
\begin{aligned}
& \eta\left(\left(x_{1}, x_{2}\right),\left(y_{1}, y_{2}\right)\right)=d\left(x_{1}, y_{1}\right)+d\left(x_{2}, y_{2}\right) ; \\
& \delta\left(\left(x_{1}, x_{2}\right),\left(y_{1}, y_{2}\right)\right)=\max \left\{d\left(x_{1}, y_{1}\right), d\left(x_{2}, y_{2}\right)\right\},
\end{aligned}
$$

for all $\left(x_{1}, x_{2}\right),\left(y_{1}, y_{2}\right) \in X \times X$, are metrics on $X \times X$.

Now, define the mapping $T: X^{2} \times X^{2}$ by

$$
\mathrm{T}(x, y)=(F(x, y), F(y, x)), \quad \forall(x, y) \in X \times X .
$$


Lemma 2.2 ([18]). The following properties hold:

(a) $(\mathrm{X}, \mathrm{d})$ is complete if and only if $\left(\mathrm{X}^{2}, \eta\right)$ and $\left(\mathrm{X}^{2}, \delta\right)$ are complete;

(b) $\mathrm{F}$ has the mixed monotone property if and only if $\mathrm{T}$ is monotone non-decreasing with respect to $\leqslant_{2}$;

(c) $(x, y) \in X \times X$ is a coupled fixed point of $F$ if and only if $(x, y)$ is a fixed point of $T$.

\section{Main results}

Theorem 3.1. Let $\mathrm{X}$ be a partially ordered set and suppose that there exists a metric $\mathrm{d}$ in $\mathrm{X}$ such that $(\mathrm{X}, \mathrm{d})$ is a complete $\mathrm{b}$-metric space with constant $\mathrm{s} \geqslant 1$. Let $\mathrm{T}: \mathrm{X} \longrightarrow \mathrm{X}$ be a nondecreasing mapping such that

$$
d(T x, T y) \leqslant \phi(d(x, y)), \quad \forall x \geqslant y,
$$

for each $x, y \in X$, where $\phi:[0,+\infty) \longrightarrow[0,+\infty)$ is increasing and satisfies

$$
\lim _{n \rightarrow \infty} \phi^{n}(t)=0, \quad \forall t>0 \text {. }
$$

Furthermore, the following conditions are satisfied:

$\left(\mathrm{H}_{1}\right)$ If $\left\{\mathrm{x}_{\mathrm{n}}\right\}$ is a non-decreasing sequence in $\mathrm{X}$ such that $\mathrm{x}_{\mathrm{n}} \longrightarrow \mathrm{x}$ as $\mathrm{n} \longrightarrow \infty$, then $\mathrm{x}_{\mathrm{n}} \leqslant \mathrm{x}$ for all $\mathrm{n} \in \mathbb{N}$;

$\left(\mathrm{H}_{2}\right)$ for $\mathrm{x}, \mathrm{y} \in \mathrm{X}$ there exists $z \in \mathrm{X}$ which is comparable to $\mathrm{x}$ and $\mathrm{y}$.

If there exists $x_{0} \in X$ such that $x_{0} \leqslant T x_{0}$. Then $T$ has a unique fixed point $x^{*} \in X$, and $\lim _{n \rightarrow \infty} T^{n}(x)=x^{*}$ for each $x \in X$.

Proof. Since T is a non-decreasing function, we obtain by induction that

$$
x_{0} \leqslant T x_{0} \leqslant T^{2} x_{0} \leqslant T^{3} x_{0} \leqslant \cdots \leqslant T^{n} x_{0} \leqslant \cdots
$$

Now, let $x \in X$ and let $\epsilon>0$ be arbitrary. Choose $n_{0} \in \mathbb{N}$ so that $\phi^{n_{0}}(\epsilon)<\frac{\epsilon}{2 s}$. Put $x_{m+1}=\left(T^{n_{0}}\right) x_{m}, m=$ $0,1,2, \cdots$. Then, from (3.1) and, as the $\mathrm{T}^{\mathrm{n}_{0} \mathrm{~m}+\mathrm{n}_{0}-\mathrm{i}} \mathrm{x}_{0}$ and $\mathrm{T}^{\mathrm{n}_{0} \mathrm{~m}-\mathrm{i}} \mathrm{x}_{0}\left(i=1,2, \cdots, \mathrm{n}_{0} \mathrm{~m}\right)$ are comparable, we obtain

$$
\begin{aligned}
d\left(x_{m+1}, x_{m}\right) & =d\left(\left(T^{n_{0}}\right)^{m+1} x_{0},\left(T^{n_{0}}\right)^{m} x_{0}\right) \\
& \leqslant \phi\left(d\left(T^{n_{0} m+n_{0}-1} x_{0}, T^{n_{0} m-1} x_{0}\right)\right) \\
& \leqslant \phi\left(\phi\left(d\left(T^{n_{0} m+n_{0}-2} x_{0}, T^{n_{0} m-2} x_{0}\right)\right)\right) \\
& =\phi^{2}\left(d\left(T^{n_{0} m+n_{0}-2} x_{0}, T^{n_{0} m-2} x_{0}\right)\right) \\
& \leqslant \cdots \\
& \leqslant \phi^{n_{0}}\left(d\left(T^{n_{0} m} x_{0}, T^{n_{0} m-n_{0}} x_{0}\right)\right) \\
& \leqslant \phi^{n_{0}}\left(\phi\left(d\left(T^{n_{0} m-1} x_{0}, T^{n_{0} m-n_{0}-1} \chi_{0}\right)\right)\right) \\
& \leqslant \phi^{n_{0}}\left(\phi^{2}\left(d\left(T^{n_{0} m-2} x_{0}, T^{n_{0} m-n_{0}-2} x_{0}\right)\right)\right) \\
& \leqslant \cdots \\
& \leqslant \phi^{n_{0}}\left(\phi^{n_{0} m-n_{0}}\left(d\left(T^{n_{0}} x_{0}, T^{0} x_{0}\right)\right)\right) \\
& =\phi^{n_{0} m}\left(d\left(T^{n_{0}} x_{0}, x_{0}\right)\right) .
\end{aligned}
$$

So $\lim _{m \rightarrow \infty} d\left(x_{m+1}, x_{m}\right)=0$.

Next, choose $M \in \mathbb{N}$ so that $d\left(x_{m+1}, x_{m}\right)<\frac{\epsilon}{2 s}$ for $m \geqslant M$. In the following, we claim that if 
$d\left(u, x_{M}\right) \leqslant \epsilon$, then $d\left(T^{n_{0}} u, x_{M}\right) \leqslant \epsilon$ with $u \geqslant x_{M}$. It follows from (3.1) that

$$
d\left(T^{n_{0}} u, T^{n_{0}} x_{M}\right) \leqslant \phi^{n_{0}}\left(d\left(u, x_{M}\right)\right) \leqslant \phi^{n_{0}}(\epsilon)<\frac{\epsilon}{2 s},
$$

and

$$
\mathrm{d}\left(\mathrm{T}^{\mathrm{n}_{0}} \chi_{M}, \chi_{M}\right)<\frac{\epsilon}{2 \mathrm{~s}}
$$

By the related triangle inequality

$$
d\left(T^{n_{0}} u, x_{M}\right) \leqslant s\left[d\left(T^{n_{0}} u, T^{n_{0}} \chi_{M}\right)+d\left(T^{n_{0}} \chi_{M}, x_{M}\right)\right]<s\left(\frac{\epsilon}{2 s}+\frac{\epsilon}{2 s}\right)=\epsilon .
$$

Note that $d\left(x_{M+1}, x_{M}\right) \leqslant \epsilon$. Our claim implies that $d\left(T^{n_{0}} x_{M+1}, x_{M}\right) \leqslant \epsilon$, i.e., $d\left(x_{M+2}, x_{M}\right) \leqslant \epsilon$, and $d\left(T^{n_{0}} x_{M+2}, x_{M}\right) \leqslant \epsilon$, i.e., $d\left(x_{M+3}, x_{M}\right) \leqslant \epsilon$. Continuing this process, we can deduce that $d\left(x_{M+i}, x_{M}\right) \leqslant$ $\epsilon(i=1,2, \cdots)$. Therefore, for $j, t \geqslant m$,

$$
d\left(x_{t}, x_{j}\right) \leqslant s\left[d\left(x_{t}, x_{M}\right)+d\left(x_{M}, x_{j}\right)\right] \leqslant 2 s \epsilon .
$$

This proves that $\left\{x_{n}\right\}$ is a Cauchy sequence. So there exists $x^{*} \in X$ such that $\lim _{m \rightarrow \infty} x_{m}=x^{*}$. From condition $\left(\mathrm{H}_{1}\right)$, we have $x_{m} \leqslant x^{*}$. Again combining (3.1), we have

$$
d\left(T^{n_{0}}\left(x^{*}\right), T^{n_{0}}\left(x_{m}\right)\right) \leqslant \phi^{n_{0}}\left(d\left(x^{*}, x_{m}\right)\right) \longrightarrow 0(m \longrightarrow \infty) .
$$

Thus $d\left(T^{n_{0}}\left(x^{*}\right), x^{*}\right)=0$, i.e., $T^{n_{0}}\left(x^{*}\right)=x^{*}$. The increasing property of $T$ tells us that $T\left(x^{*}\right)=x^{*}$. This completes the proof of Theorem 3.1.

In the same arguments as the proof of Theorem 2.1 and 2.4 in [18], and combining Lemma 2.2, we can obtain the following corollary.

Corollary 3.2. Let $(\mathrm{X}, \mathrm{d})$ be a complete $\mathrm{b}$-metric space with $\mathrm{s} \geqslant 1$ and $\mathrm{T}: \mathrm{X} \times \mathrm{X} \longrightarrow \mathrm{X}$ a mixed monotone operator on $\mathrm{X} \times \mathrm{X}$. Assume that the following conditions are satisfied:

(i) there exists $\mathrm{k} \in[0,1)$ such that

$$
d(T(x, y), T(u, v)) \leqslant \frac{k}{2}[d(x, u)+d(y, v)], \quad \forall x \geqslant u, y \leqslant v,
$$

or

$$
d(T(x, y), T(u, v)) \leqslant k \max \{d(x, u), d(y, v)\}, \quad \forall x \geqslant u, y \leqslant v ;
$$

(ii) $\mathrm{X}$ has the following properties:

$\left(X_{1}\right)$ if a non-decreasing sequence $\left\{x_{n}\right\}$ in $X$ converges to some point $x \in X$, then $x_{n} \leqslant x$ for all $n \in \mathbb{N}$,

$\left(X_{2}\right)$ if a non-increasing sequence $\left\{y_{n}\right\}$ in $X$ converges to some point $y \in X$, then $y_{n} \geqslant y$ for all $n \in \mathbb{N}$;

(iii) there exist $x_{0}, y_{0} \in X$ such that $x_{0} \leqslant T\left(x_{0}, y_{0}\right)$ and $y_{0} \geqslant T\left(y_{0}, x_{0}\right)$.

Then $T$ has a coupled fixed point $\left(x^{*}, y^{*}\right) \in X \times X$. Moreover, if for all $(x, y),(u, v) \in X \times X$, there exists $\left(z_{1}, z_{2}\right) \in X \times X$ such that $(x, y) \leqslant_{2}\left(z_{1}, z_{2}\right)$ and $(u, v) \leqslant_{2}\left(z_{1}, z_{2}\right)$, we have the uniqueness of the coupled fixed point and $x^{*}=y^{*}$.

\section{An application}

In order to compare our results to the ones in [2], we shall consider the same integral equation, that is,

$$
\left\{\begin{array}{l}
u(t)=h(t)+\int_{0}^{T} k(s, t) f(s, u(s), v(s)) d s, \\
v(t)=h(t)+\int_{0}^{T} k(s, t) f(s, v(s), u(s)) d s
\end{array}\right.
$$

where $t \in[0, T]$. 
Theorem 4.1. Consider the problem (4.1) with $\mathrm{h}:[0, \mathrm{~T}] \longrightarrow \mathbb{R}$ continuous and assume that the following conditions are satisfied

(i) $f:[0, T] \times \mathbb{R}^{2} \longrightarrow \mathbb{R}$ is continuous and $\mathrm{k}:[0, \mathrm{~T}] \times[0, \mathrm{~T}] \longrightarrow \mathbb{R}_{+}$is integrable with respect to the first variable;

(ii) $f(s, \cdot, \cdot)$ has the mixed monotone property with respect to the last two variable for all $s \in[0, T]$;

(iii) there exist $\varphi, \psi:[0, \mathrm{~T}] \longrightarrow \mathbb{R}_{+}$in $\mathrm{L}^{1}[0, \mathrm{~T}]$ such that for every $\mathrm{x}_{1}, \mathrm{x}_{2}, \mathrm{y}_{1}, \mathrm{y}_{2} \in \mathbb{R}$ with $\mathrm{x}_{1} \leqslant \mathrm{y}_{1}$ and $\mathrm{x}_{2} \geqslant \mathrm{y}_{2}$ (or reversely), we have

$$
\left|f\left(s, x_{1}, x_{2}\right)-f\left(s, y_{1}, y_{2}\right)\right| \leqslant \varphi(s)\left|x_{1}-y_{1}\right|+\psi(s)\left|x_{2}-y_{2}\right| \forall s \in[0, T] ;
$$

(iv) $\max _{\mathrm{t} \in[0, \mathrm{~T}]}\left(\int_{0}^{\mathrm{T}} \mathrm{k}(\mathrm{s}, \mathrm{t}) \varphi(s) \mathrm{ds}\right)^{2}+\max _{\mathrm{t} \in[0, \mathrm{~T}]}\left(\int_{0}^{\mathrm{T}} \mathrm{k}(\mathrm{s}, \mathrm{t}) \psi(\mathrm{s}) \mathrm{d} s\right)^{2}<\frac{1}{2} ;$

(v) there exist $\mathrm{u}_{0}, v_{0} \in \mathrm{C}[0, \mathrm{~T}]$ such that

$$
\left\{\begin{array}{l}
u_{0}(t) \leqslant h(t)+\int_{0}^{T} k(s, t) f\left(s, u_{0}(s), v_{0}(s)\right) d s \\
v_{0}(t) \geqslant h(t)+\int_{0}^{T} k(s, t) f\left(s, v_{0}(s), u_{0}(s)\right) d s
\end{array}\right.
$$

for all $\mathrm{t} \in[0, \mathrm{~T}]$.

Then there exists a unique solution $\left(x^{*}, y^{*}\right)$ of the system (4.1).

Proof. We consider the following b-metric on $\mathrm{X}$ :

$$
\mathrm{d}(\mathrm{x}, \mathrm{y}):=\max _{\mathrm{t} \in[0, \mathrm{~T}]}(x(\mathrm{t})-\mathrm{y}(\mathrm{t}))^{2} .
$$

Notice that $d$ is a b-metric with constant $s=2$.

Define the operator $\mathrm{F}: \mathrm{X} \times \mathrm{X} \longrightarrow \mathrm{X}$ by

$$
\mathrm{F}(\mathrm{u}, v)(\mathrm{t})=\mathrm{h}(\mathrm{t})+\int_{0}^{\mathrm{T}} \mathrm{k}(\mathrm{s}, \mathrm{t}) \mathrm{f}(\mathrm{s}, \mathrm{u}(\mathrm{s}), v(\mathrm{~s})) \mathrm{ds}, \quad \forall \mathrm{t} \in[0, \mathrm{~T}] .
$$

Then problem (4.1) is equivalent to find $\left(x^{*}, y^{*}\right)$ that is a coupled fixed point of $F$.

For all $(x \geqslant u$ and $y \leqslant v)$ or $(u \geqslant x$ and $v \leqslant y)$, we have

$$
\begin{aligned}
|F(x, y)(t)-F(u, v)(t)|^{2} \leqslant & 2 \max _{t \in[0, T]}\left(\int_{0}^{T} k(s, t) \varphi(s) d s\right)^{2} \max _{t \in[0, T]}(x(t)-u(t))^{2} \\
& +2 \max _{t \in[0, T]}\left(\int_{0}^{T} k(s, t) \psi(s) d s\right)^{2} \max _{t \in[0, T]}(y(t)-v(t))^{2} .
\end{aligned}
$$

Thus, taking the maximum over $t \in[0, T]$, we obtain

$$
d(F(x, y), F(u, v)) \leqslant c_{1} d(x, u)+c_{2} d(y, v) \leqslant\left(c_{1}+c_{2}\right) \max \{d(x, u), d(y, v)\},
$$

where $c_{1}:=2 \max _{t \in[0, T]}\left(\int_{0}^{T} k(s, t) \varphi(s) d s\right)^{2}$ and $c_{2}:=2 \max _{t \in[0, T]}\left(\int_{0}^{T} k(s, t) \psi(s) d s\right)^{2}$. Since $c_{1}+c_{2}<1$, we see that all the assumptions of Corollary 3.2 are satisfied and the conclusion follows. 


\section{Acknowledgment}

This project is supported by the Natural Science Foundation of Shanxi Province (2016011003) and the National Natural Science Foundation of China (No. 61603351).

\section{References}

[1] V. Berinde, Coupled fixed point theorems for $\phi$-contractive mixed monotone mappings in partially ordered metric spaces, Nonlinear Anal., 75 (2012), 3218-3228. 1

[2] M. F. Bota, A. Petruşel, G. Petruşel, B. Samet, Coupled fixed point theorems for single-valued operators in b-metric spaces, Fixed Point Theory Appl., 2015 (2015), 15 pages. 1, 1.2, 1, 4

[3] C.-F. Chen, J. Dong, C.-X. Zhu, Some fixed point theorems in b-metric-like spaces, Fixed Point Theory Appl., 2015 (2015), 10 pages. 1

[4] S. Czerwik, Contraction mappings in b-metric spaces, Acta Math. Inform. Univ. Ostraviensis, 1 (1993), 5-11. 1, 1.1, 1

[5] S. Czerwik, Nonlinear set-valued contraction mappings in b-metric spaces, Atti Sem. Mat. Fis. Univ. Modena, 46 (1998), 263-276. 1, 1.1

[6] N. V. Dung, V. T. L. Hang, On relaxations of contraction constants and Caristi's theorem in b-metric spaces, J. Fixed Point Theory Appl., 18 (2016), 267-284. 1, 1

[7] P. Eloe, R. H. Liu, Upper and lower solutions for regime-switching diffusions with applications in financial mathematics, SIAM J. Appl. Math., 71 (2011), 1354-1373. 1

[8] T. Gnana Bhaskar, V. Lakshmikantham, Fixed point theorems in partially ordered metric spaces and applications, Nonlinear Anal., 65 (2006), 1379-1393. 1

[9] D. J. Guo, V. Lakshmikantham, Coupled fixed points of nonlinear operators with applications, Nonlinear Anal., 11 (1987), 623-632. 1

[10] D. J. Guo, V. Lakshmikantham, Nonlinear problems in abstract cones, Notes and Reports in Mathematics in Science and Engineering, Academic Press, Inc., Boston, MA, (1988). 1

[11] W. Kirk, N. Shahzad, Fixed point theory in distance spaces, Springer, Cham, (2014). 1, 1

[12] N. V. Luong, N. X. Thuan, Coupled fixed points in partially ordered metric spaces and application, Nonlinear Anal., 74 (2011), 983-992. 1

[13] H. K. Nashine, Z. Kadelburg, Cyclic generalized $\varphi$-contractions in b-metric spaces and an application to integral equations, Filomat, 28 (2014), 2047-2057. 1

[14] V. I. Opŏ̌cev, Heterogeneous and combined-concave operators, (Russian) Sibirsk. Mat. Ž., 16 (1975), 781-792. 1

[15] S. Radenović, T. Došenović, T. A. Lampert, Z. Goluboví́, A note on some recent fixed point results for cyclic contractions in b-metric spaces and an application to integral equations, Appl. Math. Comput., 273 (2016), 155-164. 1

[16] A. Roldán, J. Martínez-Moreno, C. Roldán, Y. J. Cho, Multidimensional fixed point theorems under ( $\psi, \phi)$-contractive conditions in partially ordered complete metric spa, J. Comput. Appl. Math., 273 (2015), 76-87. 1, 1

[17] A. Roldán, J. Martínez-Moreno, C. Roldán, E. Karapınar, Some remarks on multidimensional fixed point theorems, Fixed Point Theory, 15 (2014), 545-558. 1

[18] B. Samet, E. Karapınar, H. Aydi, V. Ćojbašić Rajić, Discussion on some coupled fixed point theorems, Fixed Point Theory Appl., 2013 (2013), 12 pages. 1, 1, 2.2, 3 